\title{
POLÍTICAS PÚBLICAS NA AMAZÔNIA MARAJOARA: OS ÍNDICES DE DESENVOLVIMENTO SOCIOECONOMICO NA REGIÃO
}

\author{
Simei Santos Andrade ${ }^{1}$
}

\begin{abstract}
RESUMO
O estudo que ora apresentamos trata dos índices de desenvolvimento social na região da Amazônia Marajoara, por meio de alguns indicadores sociais: IDHM, IDEB, IBEU-Municipal e IDSUS. A pesquisa se deu por meio de uma abordagem qualitativa baseada numa etnografia que analisa a situação socioeconômica dos municípios e da população paraense, principalmente da Mesorregião do Marajó. Os instrumentos de pesquisa utilizados foram a observação participante, conversas informais, análises bibliográficas, documentais e relatórios que mostram a situação dos amazônidas. Os interlocutores da pesquisa foram 13 (treze) pessoas: senhores na faixa etária de 70 a 88 anos (4), jovens estudantes do Ensino Fundamental anos finais (3), estudantes do Ensino Médio (3), com idades entre 12 e 17 anos e crianças entre 7 a 11 anos (3). As conclusões a que o estudo chegou mostram que a situação do Pará no mapa das políticas de atendimento à população em relação aos direitos sociais, estabelecidos pela Constituição Federal de 1988, ainda se configura como uma realidade de pouco interesse governamental (federal, estadual e municipal), afetando principalmente crianças e idosos. A falta de políticas de enfrentamento que diminuam o abandono a que estão subjugados os paraenses, principalmente os das áreas rurais, mostra o verdadeiro abismo que existe entre o que propõe o Estado e o que realmente é disponibilizado a eles. As políticas públicas ainda estão longe de atender às reais necessidades das populações periféricas do Brasil, da Amazônia e do Pará.
\end{abstract}

Palavras-chave: Pará. Amazônia Marajoara. Desenvolvimento socioeconômico. Indicadores Sociais.

\begin{abstract}
The present study deals with social development indices in the Marajoara Amazon region, through some social indicators: IDHM, IDEB, IBEU-Municipal and IDSUS. The research was carried out through a qualitative approach based on an ethnography that analyzes the socioeconomic situation of the municipalities and the paraense population, mainly of the Marajo Meso-region. The research instruments used were participant observation, informal conversations, bibliographical analyzes, documentaries and reports that show the situation of the Amazonians. The research participants were 13 (thirteen) people: 70-88 year olds (4), junior high school students (3), high school students (3), ages 12-17 and children between 7 and 11 years old (3). The conclusions reached by the study show that the situation of Para in the map of the policies of assistance to the population in relation to social rights, established by the Federal Constitution of 1988, is still a reality of little governmental interest (federal, state and municipal) ), mainly affecting children and the elderly. The lack of coping policies that diminish the abandonment to which the Paraenses are subjected, especially those in rural areas, shows the true gulf between what the State proposes and what is actually available to them. Public policies are still far from meeting the real needs of the peripheral populations of Brazil, the Amazon and Pará.
\end{abstract}

Keywords: Pará. Amazônia Marajoara. Socioeconomic development. Social Indicators.

\footnotetext{
${ }^{1}$ Doutora em Educação, Professora da Universidade Federal do Pará, Instituto de Ciências da Arte, Escola de Teatro e Dança da UFPA. E-mail: simeiandrade@uol.com.br
} 


\section{INTRODUÇÃO}

Oriundo da língua tupi-guarani, o termo "pará" significa mar. O Estado do Pará possui uma bacia hidrográfica considerável “[...] composta por rios, lagos, paranás, furos e igarapés, contribuindo para o grande índice pluviométrico da região [...]" (CASTRO, 2013, p. 90), com ênfase para os rios Amazonas, Tocantins, Araguaia, Tapajós, Xingu, Pará, Guamá, Trombetas, Jari, Capim, Moju e Nhamundá.

Localizado na Amazônia Oriental ${ }^{2}$, é o segundo maior Estado brasileiro em extensão territorial, conforme dados do IBGE (2010d), com uma área de 1.247.954,32 km², o que corresponde a $14,66 \%$ do território brasileiro; possui 144 municípios e uma população de 7.581.051 habitantes, sendo que a estimativa para 2015 era de 8.175 .113 habitantes. O Estado está dividido em 6 (seis) mesorregiões: Baixo Amazonas, Marajó, Metropolitana de Belém, Nordeste, Sudeste e Sudoeste Paraense, subdivididas em 22 (vinte e duas) microrregiões. Faz fronteira a oeste com os Estados do Maranhão e Tocantins; ao Sul com o Estado do Mato Grosso; a leste com os Estados do Amazonas e Roraima; ao norte com o Estado do Amapá e com os países do Suriname e Guiana (CASTRO, 2013). O mapa a seguir mostra a localização do Pará e seus limites.

\footnotetext{
${ }^{2}$ Por meio do Decreto-Lei no 291, de 28/2/1967, a Amazônia Ocidental é constituída pela área abrangida pelos Estados do Amazonas, Acre, Rondônia e Roraima (os dois últimos transformados em estados federados a partir da CF de 1988). Com a criação da Amazônia Ocidental, os estados que não faziam parte dessa área de abrangência constituem a Amazônia Oriental, da qual fazem parte os estados do Amapá, Maranhão, Pará, Tocantins e Mato Grosso.
} 
Figura 1 - Mapa do Estado do Pará.

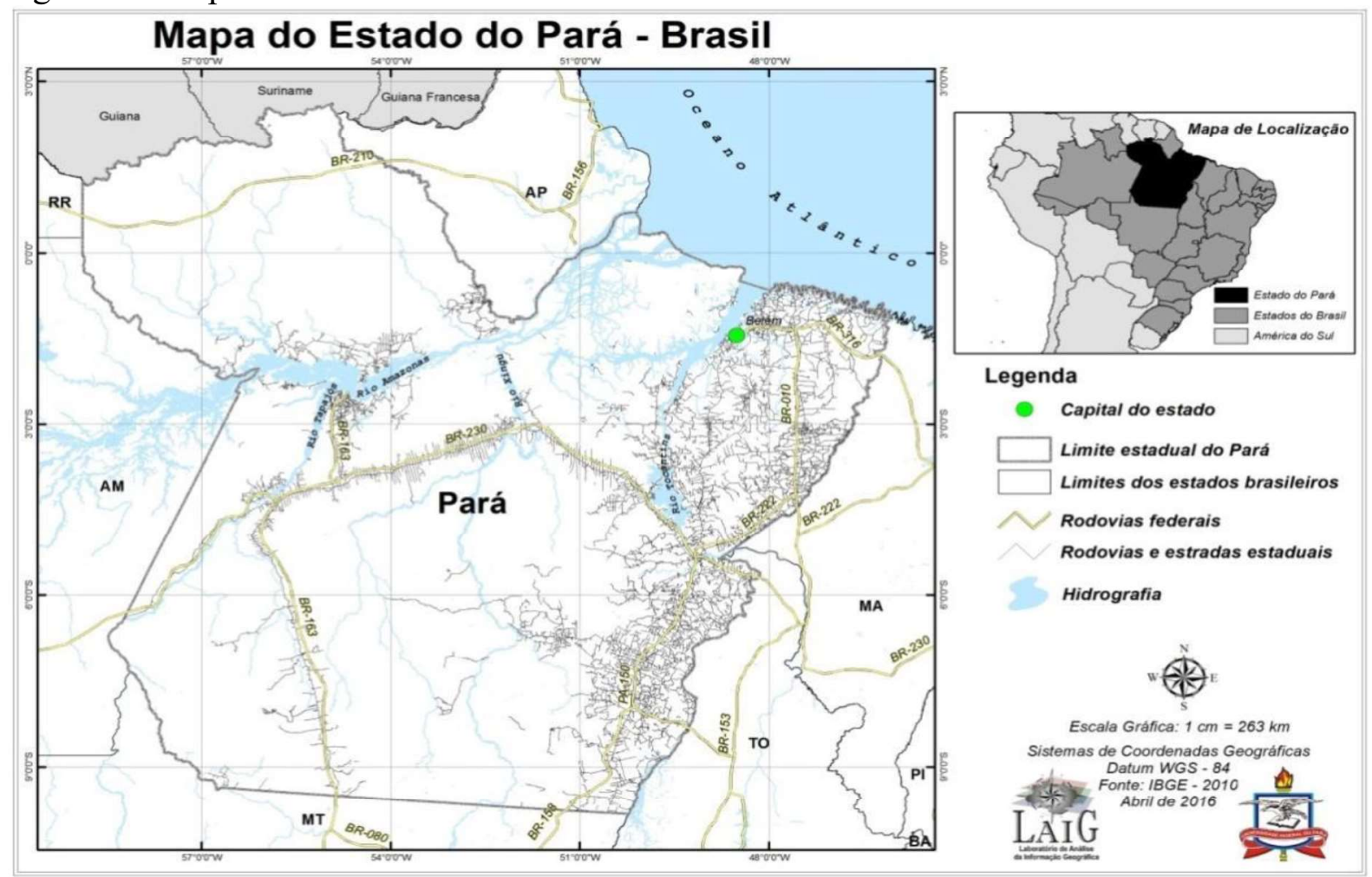

Fonte: Elaborado por LAIG/FGC/UFPA com dados extraídos de IBGE (2010c).

Comparado à sua vasta extensão territorial, o Pará apresenta um baixo índice de desenvolvimento socioeconômico, demonstrado através de alguns indicadores sociais.

Para efeito desta pesquisa não foram feitas análises densas dos IDHM, IDEB, IDSUS e IBEU- Municipal ou avaliações de processos formativos, como o educativo, por exemplo. Contudo, os dados aqui considerados trazem um panorama da situação dos municípios paraenses e consequentemente revelam a condição de vida do amazônida, refletindo os efeitos das poucas ações de políticas públicas dos governos federal, estadual e municipais (CASTRO, 2013).

Em 2013 o IBGE, por meio do PNUD, publicou o IDHM, realizado com base nos dados dos censos de 1991, 2000 e 2010, variando de 0 a 1, e que leva em conta 3 (três) indicadores: longevidade, educação e renda. O Estado do Pará ocupa a $24^{\text {a }}$ posição no ranking nacional $(0,646)$ das 27 unidades da federação, tendo ainda o município com o menor IDHM do Brasil, o município de Melgaço $(0,418)$, na Mesorregião do Marajó.

Outro dado considerável diz respeito ao IDEB, do ano de $2013^{3}$, levando em conta o total de escolas. Apenas o IDEB da $4^{\mathrm{a}}$ série $/ 5^{\mathrm{o}}$ ano do Ensino Fundamental conseguiu superar a meta proposta de 3.8, alcançando o índice de 4.0. Para a $8^{\mathrm{a}}$ série $/ 9^{\circ}$ ano do Ensino

\footnotetext{
${ }^{3}$ No momento da análise dos dados do IDEB no Estado do Pará, no sítio do Instituto Nacional de Estudos e Pesquisas Educacionais Anísio Teixeira (INEP), encontravam-se disponíveis os dados até o ano de 2013.
} 
Fundamental a meta proposta foi de 4.2, mas só atingiu 3.6; em relação à $3^{\mathrm{a}}$ série do Ensino Médio, de uma meta proposta de 3.4, atingiu-se apenas 2.9 no IDEB observado.

Em 2012 o Ministério da Saúde apresentou os dados do Índice de Desenvolvimento do Sistema Único de Saúde (IDSUS), que tem por objetivo

\section{Avaliar o desempenho do SUS quanto à: universalidade do acesso, integralidade, igualdade, resolubilidade e equidade da atenção, descentralização com comando único por esfera de gestão, responsabilidade tripartite, regionalização e hierarquização da rede de serviços de saúde (ÍNDICE DE DESEMPENHO DO SUS, 2016).}

Para efeito de avaliação, que vai de 0 a 10, foram selecionados 24 (vinte e quatro) indicadores, distribuídos em 3 (três) eixos: atenção básica, as atenções ambulatorial e hospitalar e a urgência e emergências. O estado do Pará ficou em último lugar no ranking das 27 unidades da federação, com uma avaliação de 4,17.

A situação do Pará no mapa das políticas de atendimento à população em relação aos direitos sociais, estabelecidos pela Constituição Federal de 1988, ainda se configura como uma realidade de pouco interesse governamental (federal, estadual e municipal), afetando principalmente crianças e idosos. A falta de políticas de enfrentamento que diminuam o abandono a que estão subjugados os paraenses, principalmente os das áreas rurais, mostra o verdadeiro abismo que existe entre o que propõe o Estado e o que realmente é disponibilizado a eles.

As políticas públicas ainda estão longe de atender às reais necessidades das populações periféricas do Brasil, da Amazônia e do Pará. Sobre essas questões Castro (2013) assevera o seguinte:

[...] compreende-se que o Estado do Pará é bastante diversificado, rico em recursos naturais, mas bastante desigual na distribuição e exploração desses recursos, sendo o reflexo do fracasso das políticas públicas para a Amazônia nas décadas de 1960 em diante, recebeu milhões de imigrantes, e não ofereceu infraestrutura em recebê-los, o que contribui para uma série de problemas ambientais e sociais [...] (CASTRO, 2013, p. 117).

Os problemas no Estado foram se agravando à medida que os avanços da exploração de seus recursos naturais de origem mineral (manganês, bauxita, alumina e ouro), por empresas multinacionais, foram tomando proporções gigantescas, além da exploração sem controle de madeira e a usurpação das pequenas propriedades por grileiros, expulsando o homem da região para as periferias dos centros urbanos das cidades paraenses (PINTO; KZAM, 2012; GONÇALVES, 2012). 
Em 2016 um estudo realizado pelo Observatório das Metrópoles (2016) - Instituto de Pesquisa e Planejamento Urbano e Regional da Universidade Federal do Rio de Janeiro (IPPUR/UFRJ), tornou público o Índice de Bem-Estar Urbano dos Municípios Brasileiros (IBEU-Municipal) ${ }^{4}$, calculado para todos os municípios a partir dos dados do IBGE (2010b). Este documento lista as 100 (cem) melhores e as 100 (cem) piores cidades referentes às condições de bem-estar urbano, sendo que no estado do Pará estão concentrados 41 (quarenta e um) municípios considerados os piores do Brasil.

A Mesorregião do Marajó ou Amazônia Marajoara, uma das mais pobres do Pará, é constituída por 16 (dezesseis) municípios, dentre os quais o de Curralinho, local escolhido para ser nosso campo de pesquisa. De acordo com o IBEU-Municipal, 50\% dos municípios desta mesorregião estão na condição de "os piores" em índice de bem-estar, inclusive o município alvo de nossa investigação.

Esse breve mapeamento dos indicadores sociais do Estado se fez necessário para que pudéssemos avaliar a situação socioeconômica dos municípios e da população paraense, e a partir desse quadro termos subsídios para discutir as condições das crianças da Mesorregião do Marajó, território onde se concentrou nossa pesquisa de campo.

\section{MESORREGIÃO DO MARAJÓ OU AMAZÔNIA MARAJOARA, UM ESPAÇO DE RESISTÊNCIA}

Enfrentando há séculos as intempéries naturais da região, os amazônidas aprenderam desde os primeiros processos de exploração da região pelos europeus a resistir diante das adversidades. Nesse contexto, buscamos inicialmente informações históricas que nos levassem aos primeiros grupos que habitaram os Marajós ${ }^{5}$, a fim de que pudéssemos analisar como se deu a ocupação desse arquipélago, as lutas pelo seu domínio e como as crianças se localizam nessa sociedade.

Ainda na fase Pré-histórica Tardia temos a formação das sociedades indígenas bem

\footnotetext{
${ }^{4}$ Composto por cinco dimensões: Mobilidade Urbana, Condições Ambientais Urbanas, Condições Habitacionais Urbanas, Atendimentos de Serviços Coletivos Urbanos e Infraestrutura Urbana.

${ }^{5}$ Pacheco $(2009 a, 2009 b)$, em suas pesquisas, analisa que o Arquipélago do Marajó foi reduzido pelos colonizadores à Ilha do Marajó; a diminuição não foi apenas do termo, mas da condição da população local que passa de dono da terra a subserviente de um sistema que o escraviza e o explora por séculos. Utiliza-se das expressões Marajó dos Campos e Marajó das Florestas, e "Marajós" se referindo ao arquipélago. O termo "Marajós" é o que mais observamos em seus escritos, o que se justifica por indicar que "o pluralizar de Marajó procura chamar a atenção do leitor à complexidade de realidades físicas, humanas, históricas e culturais existentes entre os municípios conformadores das regiões de campos e florestas. Essa perspectiva ainda questiona visões homogêneas e preconceituosas fabricadas pelos meios de comunicação, quando visualizam imagens de um Marajó desenhado tão somente por praias, búfalos e paisagens naturais ou por seu ilhamento físico e social" (PACHECO, 2009a, p. 438).
} 
desenvolvidas que se assentaram ao longo do rio Amazonas. Os Marajós é formado por povos diversos que se fixaram na região desde os primórdios da ocupação da Amazônia, constituindo uma sociedade - a marajoara - que, segundo dados arqueológicos, tinha um domínio avançado do trabalho com cerâmica, do qual detinha técnicas refinadas (VERÍSSIMO; PEREIRA, 2014).

Pacheco (2010) considera que existiam diversas nações indígenas ${ }^{6}$ que lutavam bravamente contra os colonizadores, que chegaram ao arquipélago com mais força a partir do século XVI, afirmando que

\begin{abstract}
O labirinto de ilhas, os "Marajós", e seus habitantes cravados na foz do território a ser conquistado, não assistiram, passivamente, àquelas estranhas chegadas de gentes tão diferentes de suas visões humanas. Experientes em contatos e guerras tribais anteriormente vividas, entre si e com outras nações, Aruãns, Sacacas, Marauanás, Caiás, Araris, Anajás, Muanás, Mapuás, Pacajás, entre outras e os batizados de Nheengaibas, enfrentaram as armas portuguesas por quase 20 anos. Esse processo já demonstra quão difícil foi a conquista da Amazônia e como os nativos habitantes, "da ilha que estava atravessada na boca do rio Amazonas, de maior comprimento e largueza que todo o reino de Portugal", posicionaram-se diante da voraz ganância lusitana (PACHECO, 2010, p. 18).
\end{abstract}

A Amazônia, como toda a América, foi afetada pela dominação colonial europeia que se expandia por todo o mundo, uma vez que "já em sua condição de centro do capitalismo mundial, a Europa não somente tinha o controle do mercado mundial, mas pôde impor seu domínio colonial sobre todas as regiões e populações do planeta [...]" (QUIJANO, 2005, p. 121).

A resistência dos habitantes da Ilha Grande de Joanes ${ }^{7}$ em defesa de suas terras, de sua cultura e dos seus modos de vida foi registrada por religiosos, cronistas, viajantes e historiadores nos séculos XVIII e XIX, além das obras regionais que tratam do tema na contemporaneidade. As populações indígenas, com habilidade de quem conhece o seu chão, eram capazes de adentrar a floresta, percorrer longos caminhos, dominavam estratégias de esconderijos, remavam com destreza em grandes e pequenos rios e manuseavam com muita propriedade arcos e flechas (PACHECO, 2010). Deste modo, percebe-se que a conquista do

\footnotetext{
${ }^{6}$ No período colonial, o arquipélago recebeu o nome de Ilha dos Nheengaíbas, entre o povo“[...] por causa das diferentes línguas - nheengatuba - de índios que ali existiam. Provavelmente esta denominação de Ilha dos Nheengaíbas foi imposta pelos colonizadores, visto que, na visão dos portugueses, Nheengaíbas significa povos de língua complicada" (SILVA, 2013, p. 22).

${ }^{7}$ Rabelo e Neves (2014) asseveram que o espanhol Vicente Pizón, no período colonial, deu ao arquipélago do Marajó o nome de Ilha Grande de Joanes, ficando assim denominada até meados do século XVII. As autoras ainda discorrem que "em 1754 a "Ilha Grande de Joanes" recebeu o nome de Marajó, que significa "o vento que sopra a tarde sobre a ilha". No entanto, a origem desse nome pode vir de Mbara-yó, que no Tupi significa "barreira do mar". Aliás, aos olhos dos antigos colonizadores, a ilha parecia servir como uma muralha erguida pela própria natureza para barrar as tormentas do oceano" (RABELO; NEVES, 2014, p. 385).
} 
arquipélago dos Marajós pelos portugueses foi uma tarefa árdua diante da oposição indígena aos europeus.

Para o enfrentamento com a população local, os portugueses trouxeram para o fundamento da civilização moderna a ideia da necessidade de domínio da natureza. As populações indígenas foram vistas como selvagem, portanto, precisavam ser dominadas. Sobre esse aspecto Gonçalves (2002) salienta que

[...] os povos a serem dominados foram assimilados à natureza começando por considerá-los selvagens, que significa, rigorosamente, os que são da selva, logo, aqueles que devem ser dominados pela cultura, pelo homem (europeu, burguês, branco e masculino) [...] (GONÇALVES, 2002, p. 218).

Quando o colonizador se autodenomina europeu civilizado cria o selvagem, assim "[...] a invenção da modernidade é inseparável da invenção da colonialidade" (GONÇALVES, 2002, p. 218). É como selvagem que a população local amazônida é escravizada, colonizada. Conflitos entre europeus e população nativa, entre populações indígenas, expropriação da terra, violência física e mortes marcam a história dos Marajós.

Em 1665, a Ilha Grande de Joanes é constituída em capitania hereditária e doada por D. Afonso VI ao capitão-mor Antônio de Sousa Macedo, secretário de estado. Soares (2010) e Pacheco (2010) indicam que a doação do arquipélago à família do capitão-mor Antônio Macedo foi uma maneira de controle e também de povoamento de um território tático com ligações com a região do Cabo Norte e com a Guiana Francesa, que eram constantemente "visitadas" por holandeses, franceses, ingleses, irlandeses, que se beneficiavam de suas riquezas. O fato de os indígenas manterem relações comerciais com outros grupos de europeus gerou ainda mais conflitos com os portugueses. A partir de então, os Marajós têm suas terras divididas e cedidas, pelo sistema de sesmarias, pelos capitães-mores para que fossem ocupadas, preferencialmente por uma elite (fidalgos e pessoas de posses), como nos referenda Teixeira (1952):

\begin{abstract}
Aproveitando-se do costume, então vigente, de concederem-se sesmarias, de preferência a pessoas fidalgas ou com posse bastante para construir engenhos, com exclusão das classes pobres e desfavorecidas, muitos súditos do rei de Portugal pediram concessões de terras em Marajó, principalmente onde pretendiam fundar fazendas de criação, alegando aos donatários, capitães-mores e governadores que "eram homens de muita posse e família" ou que "eram homens assim de gente como de criação que a um morador são pertencentes" ou que "tem muita fábrica de gado de toda a sorte e escravos como qualquer morador" (TEIXEIRA, 1952, p. 741).
\end{abstract}

\footnotetext{
${ }^{8}$ Soares (2010, p. 11) analisa em seus estudos "[...] a importância da família e do compadrio na constituição da sociedade marajoara, enfatizando as redes de relações que ensejam [...]”, nos séculos XVIII e XIX.
} 
A forma como as terras eram distribuídas no sistema de sesmarias nas demais regiões do Brasil é o mesmo que se instala no arquipélago do Marajó, com o poder econômicopolítico regendo as relações entre as famílias da sociedade marajoara. Pacheco (2010) assegura ainda que famílias importantes, religiosos, os protegidos, aqueles que já tinham terras, exigiam ainda mais o aumento delas, gerando um processo de desigualdade social que ainda hoje perdura na Amazônia - a centralização de muitas terras nas mãos de poucos latifundiários, e muitos sem um pedaço de terra para plantar e garantir uma vida com mais dignidade.

Soares (2010) e Pacheco (2010) referendam, a partir de análises documentais, que no período de 1725 a 1823 as terras do Marajó foram distribuídas e ocupadas ininterruptamente por famílias influentes na região, edificando fazendas e sítios. O Relatório Analítico do Território do Marajó, aponta que entre 1721 e 1740 foram distribuídas mais de 50 (cinquenta) sesmarias no arquipélago (UNIVERSIDADE FEDERAL DO PARÁ, 2012).

As Ordens Religiosas que se instalam na região com o objetivo de "[...] pacificar os indígenas [...]" (TAVARES, 2008, p. 60), foram consideradas estratégicas no processo de ocupação e dominação da região. No entanto, no contexto político, os interesses portugueses conflitaram com os interesses dessas organizações, o que gera a expulsão e o confísco dos bens dos jesuítas e de outras denominações religiosas posteriormente.

Pombal $^{9}$ utiliza o discurso de modernização da região para implementar uma série de medidas que visavam ao aumento do capital português e à escravidão dos nativos, a exemplo do que já ocorria em outras regiões colonizadas pelos portugueses. Nesse período sucede a "[...]: doação de terras (sesmarias) a colonos e soldados que se comprometessem a cultiválas; [...]; estímulo à pecuária no Rio Branco (Roraima), baixo Amazonas e na região das Ilhas (Marajó, inclusive)" (GONÇALVES, 2012, p. 82, grifo nosso). O Relatório Analítico do Território do Marajó (UNIVERSIDADE FEDERAL DO PARÁ, 2012, p. 14), referindo-se aos marajoaras discorre que "[...] essa população foi duramente escravizada pelos portugueses que tomaram para si grandes áreas de terras por meio de concessões de sesmarias".

Soares (2010) e Araújo (2002) dispõem que em 1760, em Carta Régia ordenado por D. José I, os bens dos jesuítas são rateados e divididos seguindo o posto hierárquico; as terras foram repartidas em 22 quinhões que se espalharam por diversas partes dos Marajós.

Além das sociedades indígenas, temos os povos europeus (portugueses, espanhóis,

\footnotetext{
${ }^{9}$ Sebastião José de Carvalho e Melo, conhecido como Marquês de Pombal, foi Primeiro-Ministro de Portugal, criou a Companhia Geral do Grão-Pará e Maranhão.
} 
franceses, ingleses, entre outros), africanos trazidos como mão de obra escrava para servir aos colonizadores e nordestinos que chegam ao final do século XIX para trabalharem na exploração da borracha. O Relatório Territorial do Marajó (2015) faz referência a esse aspecto, bem como o Instituto de Pesquisa Econômica Aplicada (IPEA, 2015) discorre que

\begin{abstract}
As terras do Marajó pertencem historicamente a inúmeras famílias que se estabeleceram na região; possuem uma ancestralidade milenar - indígena - e uma ancestralidade mais recente, porém secular, do contingente africano, trazido para servir de mão de obra escrava ao colonizador, e de nordestinos do semiárido, que migraram para a região a fim de trabalhar nas colocações de borracha da Amazônia oriental no fim do século XIX e início do XX (INSTITUTO NACIONAL DE ESTUDOS E PESQUISAS EDUCACIONAIS ANÍSIO TEIXEIRA, 2015, p. 19).
\end{abstract}

Portanto, é um território de composição étnica complexa que precisou adaptar as culturas estabelecidas a diversas outras trazidas pelos que aqui chegaram. A exploração tem sido a arma da dominação até os dias de hoje, e é por meio dela que a população local tem sido expulsa do seu chão. Mas, embora a luta seja difícil, Quijano (2005, p. 139) nos instiga a refletir que "é tempo de aprendermos a nos libertar do espelho eurocêntrico onde nossa imagem é sempre, necessariamente, distorcida. É tempo, enfim, de deixar de ser o que não somos".

Considerada a maior "ilha fluviomarinha" localizado na Mesorregião do Marajó, que possui uma população de 487.010 habitantes (INSTITUTO BRASILEIRO DE GEOGRAFIA E ESTATÍSTICA, 2010a), o que representa $6,42 \%$ da população do estado, grande parte dela vivendo na zona rural dos municípios que fazem parte dessa região (INSTITUTO BRASILEIRO DE GEOGRAFIA E ESTATÍSTICA, 2010a; PARÁ, 2012). Ressalte-se ainda que mesmo com uma população de quase quinhentos mil habitantes representa uma das menores populações entre as mesorregiões do Pará (CASTRO, 2013). O mapa a seguir mostra a localização da mesorregião no estado do Pará.

\footnotetext{
${ }^{10}$ Denominada assim porque é cercada por rios de um lado, e do outro pelo mar.
} 
Figura 2 - Mesorregião do Marajó

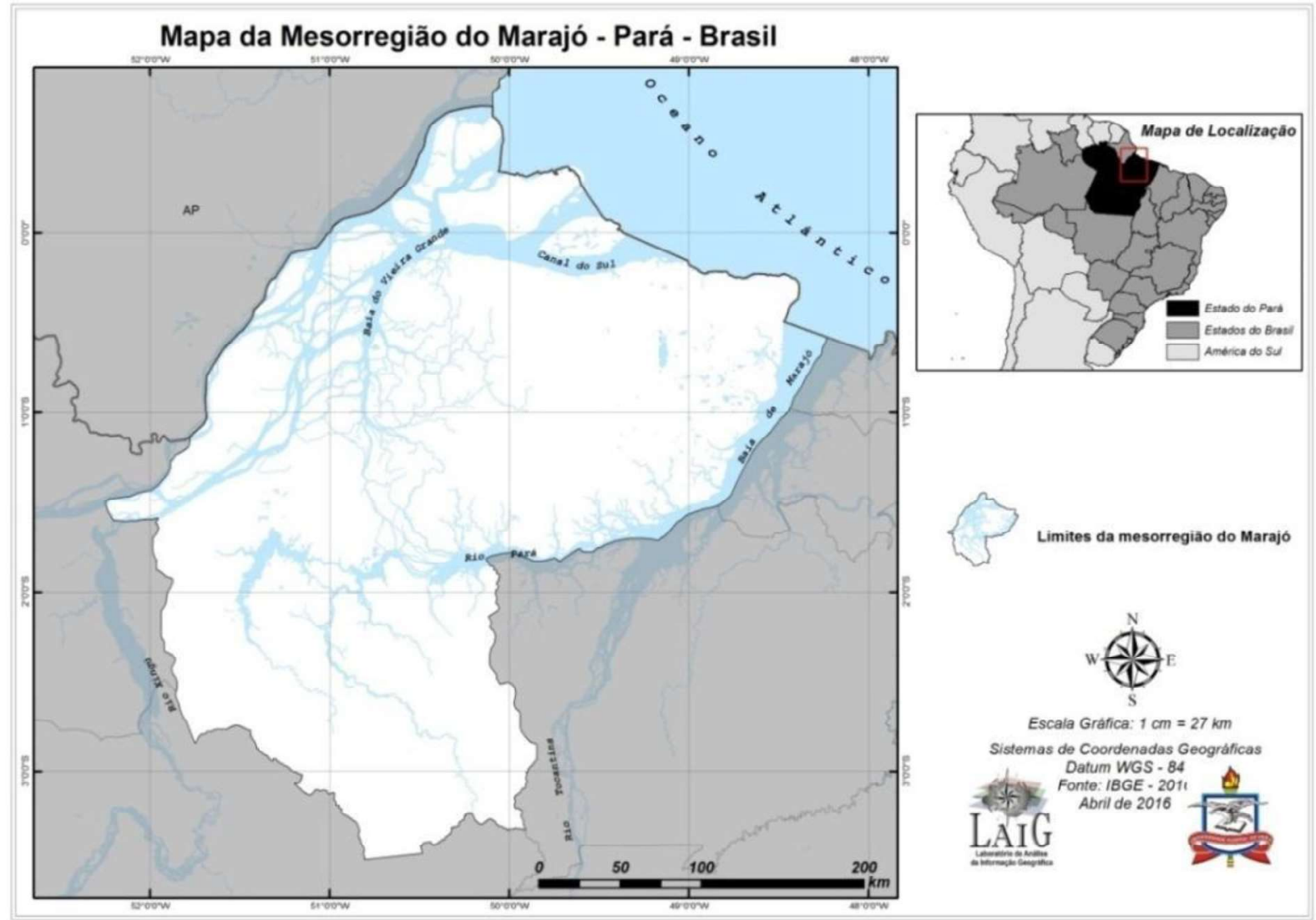

Fonte: Elaborado por LAIG/FGC/UFPA com dados extraídos de IBGE (2010b).

A distribuição de terras pelo sistema de sesmarias pode ter dado origem aos dezesseis municípios que compõem hoje o arquipélago do Marajó: Santa Cruz do Arari, Afuá, Anajás, Bagre, Breves, Cachoeira do Arari, Chaves, Curralinho, Gurupá, Melgaço, Muaná, Ponta de Pedras, Portel, Salvaterra, São Sebastião da Boa Vista e Soure. O IBGE instituiu a Divisão Regional do Brasil em Mesorregiões e Microrregiões Geográficas ${ }^{11}$ elencando os municípios nesse contexto. O arquipélago do Marajó, na Mesorregião do Marajó, está subdividido em 3 (três) Microrregiões (Portel, Furos de Breves e Arari), cada microrregião agregando determinado número de municípios, conforme nos mostra a tabela abaixo:

Quadro 1 - Microrregiões do Marajó

\begin{tabular}{|c|c|c|}
\hline Microrregião de Portel & $\begin{array}{c}\text { Microrregião dos Furos de } \\
\text { Breves }\end{array}$ & Microrregião do Arari \\
\hline Bagre & Afuá & Cachoeira do Arari \\
Gurupá & Anajás & Chaves \\
Melgaço & Breves & Muaná \\
Portel & Curralinho & Ponta de Pedras \\
\hline
\end{tabular}

${ }^{11}$ Foi aprovada pela Presidência do IBGE através da Resolução PR-51, de 31/07/89, publicada no Suplemento do Boletim de Serviço da Instituição $n^{\circ}$ 1763, semanas 927 a 931, Ano XXXVIII, de circulação interna (INSTITUTO BRASILEIRO DE GEOGRAFIA E ESTATÍSTICA 1990, p. 5). 


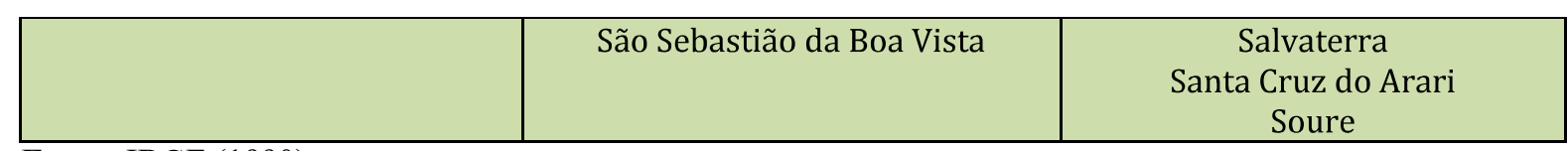

Fonte: IBGE (1990).

Embora a Mesorregião do Marajó seja uma das mais belas do estado do Pará, em se tratando de beleza natural, os seus municípios dispostos nas três Microrregiões não traduzem nos índices de desenvolvimento social o que se observa na imensidão dos rios e nos verdes das matas. Os índices se assentam do nível baixo para o muito baixo na maior parte dos municípios, o que significa que há insuficiência ou ausência de políticas públicas capazes de atender a população no que diz respeito aos seus direitos sociais e assegurar às crianças, jovens e adultos uma condição de vida menos desigual. Sobre a situação da mesorregião, Castro (2013) considera que

A paisagem da mesorregião é bastante diversificada, apresentando área de mangue, campos naturais e floresta [...]. Porém, o contraste é grande na ilha, a população é uma das mais pobres do Pará, a prostituição, as doenças e a falta de infraestrutura para a população local contradiz toda a beleza natural (CASTRO, 2013, p. 117).

Uma consequência imediata desse descaso percebe-se nos resultados apresentados no IDHM, que é uma medida composta de indicadores (longevidade, educação e renda), e que possibilita mostrar os anos de vida que os sujeitos viveriam a partir do nascimento, levando em conta os mesmos padrões de mortalidade observados no ano de referência; os indicadores de escolaridade da população adulta e do fluxo escolar da população jovem; e ainda a renda per capita do município (PROGRAMA DAS NAÇÕES UNIDAS PARA O DESENVOLVIMENTO, 2016).

Os municípios brasileiros foram classificados de acordo com sua posição em uma tabela que vai do maior para o menor índice (muito alto, alto, médio, baixo e muito baixo). De um total de $5.570^{12}$ municípios no território nacional, o município que ostenta o maior índice é São Caetano do Sul/SP $(0,862)$, enquanto que o município que se apresenta com o menor índice é o de Melgaço/PA (0,418), localizado na Mesorregião do Marajó.

O IDHM da Mesorregião do Marajó aponta que dos 16 (dezesseis) municípios, 6 (seis) apresentam IDHM $^{13}$ "muito baixo", que varia de 0,000 - 0,499, representando $37,5 \%$ dos municípios; 8 (oito) municípios têm o IDHM "baixo", variando de 0,500 - 0,599,

\footnotetext{
${ }^{12} \mathrm{Em} 1^{\circ}$ de janeiro de 2013 foram criados cinco novos municípios. São eles: Pescaria Brava e Balneário Rincão, em Santa Catarina; Mojuí dos Campos, no Pará; Pinto Bandeira, no Rio Grande do Sul e Paraíso das Águas, no Mato Grosso do Sul.

${ }^{13} \mathrm{O}$ índice varia de 0 a 1 . Quanto mais próximo de 1, maior o desenvolvimento humano (PNUD, 2016).
} 
representando $50 \%$ dos municípios marajoaras; e, apenas dois ${ }^{14}$ (2) municípios estão entre aqueles que têm o IDHM médio, numa variação que vai de 0,600 - 0,699, chegando a apenas 12,5\% dos municípios da Mesorregião do Marajó. O quadro a seguir sintetiza a situação da Mesorregião:

Quadro 2 - Demonstrativo da situação dos municípios da Mesorregião do Marajó em relação ao IDHM (2010).

\begin{tabular}{|c|c|c|c|c|}
\hline Município & $\begin{array}{l}\text { IDH-M } \\
(2010)\end{array}$ & Faixa do IDH-M & $\begin{array}{l}\text { Ranking } \\
\text { Nacional }\end{array}$ & $\begin{array}{l}\text { Ranking } \\
\text { Estadual }\end{array}$ \\
\hline \multicolumn{5}{|c|}{ Microrregião de Portel } \\
\hline Bagre & 0,471 & Muito Baixo & $5558^{\underline{a}}$ & $141^{\circ}$ \\
\hline Gurupá & 0,509 & Baixo & $5502^{a}$ & $28^{\circ}$ \\
\hline Melgaço & 0,418 & Muito Baixo & $\begin{array}{c}\text { 5565a (Menor IDH-M do } \\
\text { Brasil) }\end{array}$ & $143^{\circ}$ \\
\hline Portel & 0,483 & Muito Baixo & $5553^{\mathrm{a}}$ & $139^{\circ}$ \\
\hline \multicolumn{5}{|c|}{ Microrregião dos Furos de Breves } \\
\hline Afuá & 0,489 & Muito Baixo & $5543^{\mathrm{a}}$ & $136^{\circ}$ \\
\hline Anajás & 0,484 & Muito Baixo & $5550^{\mathrm{a}}$ & $138^{\circ}$ \\
\hline Breves & 0,503 & Baixo & $5520^{\underline{a}}$ & $132^{\circ}$ \\
\hline Curralinho & 0,502 & Baixo & $5524^{\mathrm{a}}$ & $134^{\circ}$ 은 \\
\hline $\begin{array}{c}\text { São Sebastião da } \\
\text { Boa Vista }\end{array}$ & 0,558 & Baixo & $5081^{a}$ & $97^{\circ}$ \\
\hline \multicolumn{5}{|c|}{ Microrregião do Arari } \\
\hline Cachoeira do Arari & 0,546 & Baixo & $5253^{a}$ & $109^{\circ}$ \\
\hline Chaves & 0,453 & Muito Baixo & $5.565^{\mathrm{a}}$ & $142^{\circ}$ \\
\hline Muaná & 0,547 & Baixo & $5244^{\mathrm{a}}$ & $106^{\circ}$ \\
\hline Ponta de Pedras & 0,562 & Baixo & $5002^{\mathrm{a}}$ & $92^{\circ}$ \\
\hline Salvaterra & 0,608 & Médio & 3957 a & $40^{\circ}$ \\
\hline $\begin{array}{c}\text { Santa Cruz do } \\
\text { Arari }\end{array}$ & 0,557 & Baixo & $5098^{a}$ & $98^{\circ}$ \\
\hline Soure & 0,615 & Médio & $3796^{\underline{a}}$ & $35^{\circ}$ \\
\hline
\end{tabular}

Fonte: PNUD (2010).

Os municípios dessa região apresentam deficiência na qualidade dos serviços destinados ao atendimento da população, merecendo destaque a falta de oportunidades de trabalho, de terras para plantar, de saneamento básico, do funcionamento sem o mínimo de qualidade dos serviços de saúde, principalmente na zona rural, onde médicos, enfermeiros, odontólogos, bioquímicos e demais profissionais são raridade, o que pode contribuir para elevar ainda mais a mortalidade infantil. O acompanhamento pré-natal é precário, o cronograma de vacinação

${ }^{14}$ Os municípios de Soure e Salvaterra possuem uma infraestrutura turística considerável (hotéis e pousadas, restaurantes regionais, passeios turísticos, entre outros), além de uma estrutura rodo fluvial com viagens diárias. 
das crianças nem sempre é cumprido, a gravidez na adolescência cresce de maneira assustadora, a violência contra a integridade de crianças e de mulheres tem sequestrado a vida de muitos cidadãos, além do aumento do tráfico e consumo de drogas nos centros urbanos e rurais das cidades amazônicas, índices consideráveis de analfabetismo entre os adultos, escolas em precárias condições estruturais de funcionamento, falta de merenda escolar, falta de combustível para atender o transporte escolar (ônibus e barcos), exploração sexual de crianças e adolescentes.

A esse respeito o Relatório Analítico do Território do Marajó ${ }^{15}$ mostra a situação a que está submetida a população dessa parte do Brasil.

Os indicadores socioeconômicos e culturais mostram que essa região foi historicamente abandonada pela ausência ou baixa capilaridade das políticas públicas, de serviços infraestruturais e de equipamentos coletivos de promoção e proteção social voltados ao desenvolvimento sócio-territorial. Nesse sentido, há a necessidade de uma mobilização produtiva dos sujeitos sociais, para dinamizar as capacidades institucionais em busca dessas necessidades essenciais, a fim de potencializar os meios existentes no território.

A ausência de infraestrutura e de equipamentos de uso coletivo tem produzido problemas de ordens diversas, como fome, miséria, altos índices de malária, em determinados municípios, abuso e exploração sexual de crianças e adolescentes etc. (UNIVERSIDADE FEDERAL DO PARÁ, 2012, p. 4).

O Relatório apresenta dados alarmantes sobre os municípios da Mesorregião do Marajó, mostrando que as precárias condições de saneamento refletem diretamente na condição de vida da população, alertando para o consumo de água contaminada por dejetos fecais, causando doenças infecciosas e parasitárias, vitimando principalmente as crianças. Referindo-se às condições sanitárias, o Relatório dispõe que

No Marajó, na maioria das vezes, o fornecimento de água para consumo da população é feito pelo próprio rio, sendo que apenas uma proporção muito pequena faz algum tratamento dela. É necessário ressaltar que o rio não serve apenas como fornecedor de água para as necessidades básicas (cozinhar, lavar roupas, banhos), mas também como depósito de dejetos fecais, o que produz consequências danosas à saúde da população. Isso denota precárias condições de saneamento ambiental (UNIVERSIDADE FEDERAL DO PARÁ, 2012, p. 30).

Sobre esse aspecto o Relatório ressalta ainda que apenas $3,4 \%$ de toda a área do Marajó possui rede de esgoto e $29 \%$ utiliza-se de fossas; o restante $67,7 \%$ das instalações

\footnotetext{
${ }^{15}$ O Relatório foi elaborado pelas seguintes instituições parceiras: Universidade Federal do Pará, Instituto de Ciências Sociais Aplicadas, Ministério do Desenvolvimento Agrário (MDA), Programa Incubadora Tecnológica de Cooperativas Populares e Empreendimentos Solidários (PITCPES), Grupo de Estudo e Pesquisa Trabalho e Desenvolvimento na Amazônia (GPTDA), Projeto Desenvolvimento Sustentável e Gestão Estratégica dos Territórios Rurais, no Estado do Pará.
} 
sanitárias são a céu aberto, deste modo a inadequação de saneamento básico e sua díspar distribuição tem provocado a constância das taxas de desnutrição, mortalidade infanti1 ${ }^{16}$ e mortalidade na infância ${ }^{17}$ (ROSEMBERG, 2017).

Souza (2015, p. 88) discorre que grande parte da mesorregião é formada por comunidades ribeirinhas, e em qualquer uma delas a situação de pobreza material é intensa, "[...] consequência da colonização e de exploração que o Arquipélago foi submetido desde o início de sua historicidade e que tem se perpetuado até a atualidade, porém de outras maneiras"; a população local é oprimida, e pouco recebe diante do que lhe é defraudado, além da apropriação desigual de suas terras; é verdade que na região existe muita terra, mas para poucos latifundiários (GONÇALVES, 2012). Nesse contexto as tensões e conflitos se tornaram presentes entre os exploradores e a população, transformando nas últimas décadas a Amazônia em um espaço "de devastação, de exploração, de violências e resistência" (GONÇALVES, 2012, p. 13). As consequências se mostram também nos outros índices de desenvolvimento social que afetam em muito a vida das crianças e dos jovens.

Além do IDHM, que mostra a situação penosa dos ribeirinhos do Marajó, outro índice tem refletido a situação da falta de políticas públicas compromissadas com as crianças e jovens da Mesorregião, o IDEB. Em alguns municípios existem escolas que atuam nos anos iniciais e finais do Ensino Fundamental que pertencem à rede estadual e ou rede municipal de ensino, o que não indica necessariamente melhorias significativas na educação municipal, apesar da presença das duas redes de ensino trabalhando com o mesmo fim no mesmo município, redundando em índices do IDEB muito próximos e ou iguais.

Em relação à $4^{\mathrm{a}}$ série $/ 5^{\circ}$ ano do Ensino Fundamental apenas o município de Santa Cruz do Arari ${ }^{18}$ conseguiu atingir a meta estabelecida pelo Governo Federal para cada município da federação, o que corresponde a 6,25\% da Mesorregião do Marajó. Quanto ao último ano do Ensino Fundamental, $8^{\mathrm{a}}$ série $/ 9^{\circ}$ ano, a análise mostra que 5 (cinco) municípios atingiram a meta (Bagre, Melgaço, Portel, Cachoeira do Arari e Santa Cruz do Arari), aí incluídas escolas estaduais e municipais, o que dá um percentual de 31,25\% de municípios que atingiram a meta. Os dois municípios que estão classificados no IDHM como médio (Soure e Salvaterra) não conseguiram atingir a meta do IDEB, mesmo tendo uma situação econômica superior aos demais municípios, em decorrência da infraestrutura turística de que dispõem. Os quadros a seguir resumem a situação da educação na Mesorregião do Marajó em relação ao IDEB

\footnotetext{
${ }^{16}$ Que se refere à morte de crianças antes de completar 1 ano de idade (ROSEMBERG, 2017, p. 15).

${ }^{17}$ Que se refere a crianças que morrem antes de completar 5 anos de idade (ROSEMBERG, 2017,p. 15).

${ }^{18}$ Município pertencente à Microrregião do Arari.
} 
(2013).

Quadro 3 - Demonstrativo da situação dos municípios da Microrregião de Portel em relação ao IDEB (2013).

\begin{tabular}{|c|c|c|c|c|c|}
\hline $\begin{array}{c}\text { Municípi } \\
\text { o } \\
\end{array}$ & Série/Ano & $\begin{array}{c}\text { IDEB } \\
\text { observado }\end{array}$ & $\begin{array}{c}\text { Meta } \\
\text { Projetada } \\
\end{array}$ & $\begin{array}{c}\text { Rede de } \\
\text { Ensino }\end{array}$ & Observação \\
\hline \multirow[t]{2}{*}{ Bagre } & $4^{a}$ série $/ 5^{\circ}$ ano & 3.3 & 3.8 & Municipal & Não atingiu a meta \\
\hline & $8^{\mathrm{a}}$ série $/ 9^{\circ}$ ano & 4.0 & 4.0 & Municipal & Atingiu a meta \\
\hline \multirow[t]{4}{*}{ Gurupá } & $4^{\mathrm{a}}$ série $/ 5^{\circ}$ ano & 2.8 & 3.4 & Municipal & Não atingiu a meta \\
\hline & $8^{\mathrm{a}}$ série $/ 9^{\circ}$ ano & 3.0 & 3.7 & Municipal & Não atingiu a meta \\
\hline & $4^{a}$ série $/ 5^{\circ}$ ano & - & - & Estadual & * \\
\hline & $8^{a}$ série $/ 9^{\circ}$ ano & - & - & Estadual & * \\
\hline \multirow[t]{4}{*}{ Melgaço } & $4^{\mathrm{a}}$ série $/ 5^{\circ}$ ano & 2.7 & 3.4 & Municipal & Não atingiu a meta \\
\hline & $8^{\mathrm{a}}$ série $/ 9^{\circ}$ ano & 3.7 & 3.3 & Municipal & Atingiu a meta \\
\hline & $4^{\text {a }}$ série $/ 5^{\circ}$ ano & - & - & Estadual & $*$ \\
\hline & $8^{\mathrm{a}}$ série $/ 9^{\circ}$ ano & 2.9 & 3.6 & Estadual & Não atingiu a meta \\
\hline \multirow[t]{2}{*}{ Portel } & $4^{a}$ série $/ 5^{\circ}$ ano & 3.3 & 3.8 & Municipal & Não atingiu a meta \\
\hline & $8^{\mathrm{a}}$ série $/ 9^{\circ}$ ano & 4.0 & 3.6 & Municipal & Atingiu a meta \\
\hline
\end{tabular}

Fonte: (INSTITUTO NACIONAL DE ESTUDOS E PESQUISAS EDUCACIONAIS ANÍSIO TEIXEIRA, 2013).

* Sem média na Prova Brasil 2013: Não participou ou não atendeu os requisitos necessários para ter o desempenho calculado.

Quadro 4 - Demonstrativo da situação dos municípios da Microrregião Furos de Breves em relação ao IDEB (2013).

\begin{tabular}{|c|c|c|c|c|c|}
\hline $\begin{array}{r}\text { M } \\
\text { unicípio }\end{array}$ & $\begin{array}{l}\text { Série/A } \\
\text { no }\end{array}$ & $\begin{array}{r}\text { IDEB } \\
\text { observado }\end{array}$ & $\begin{array}{l}\text { Meta } \\
\text { Projetada }\end{array}$ & $\begin{array}{c}\text { Re } \\
\text { de de } \\
\text { Ensino }\end{array}$ & $\begin{array}{l}\text { Observa } \\
\text { ção }\end{array}$ \\
\hline \multirow[t]{2}{*}{ uá ${ }^{\text {Af }}$} & $\begin{array}{c}4^{\mathrm{a}} \\
\text { série } / 5^{\circ} \text { ano }\end{array}$ & 2.7 & 3.5 & $\begin{array}{l}\mathrm{Mu} \\
\text { nicipal }\end{array}$ & $\begin{array}{c}\text { Não } \\
\text { atingiu a meta }\end{array}$ \\
\hline & $\begin{array}{c}8^{\mathrm{a}} \\
\text { série/9ㅇ ano }\end{array}$ & 2.9 & 4.0 & $\begin{array}{l}\mathrm{Mu} \\
\text { nicipal }\end{array}$ & $\begin{array}{c}\text { Não } \\
\text { atingiu a meta }\end{array}$ \\
\hline \multirow[t]{3}{*}{ ajás $^{\text {An }}$} & $\begin{array}{c}4^{\mathrm{a}} \\
\text { série/5a ano }\end{array}$ & 2.5 & 3.7 & $\begin{array}{l}\mathrm{Mu} \\
\text { nicipal }\end{array}$ & $\begin{array}{r}\text { Não } \\
\text { atingiu a meta }\end{array}$ \\
\hline & $\begin{array}{c}8^{\underline{a}} \\
\text { série/9a ano }\end{array}$ & 3.1 & 4.2 & $\begin{array}{l}\mathrm{Mu} \\
\text { nicipal }\end{array}$ & $\begin{array}{c}\text { Não } \\
\text { atingiu a meta }\end{array}$ \\
\hline & $\begin{array}{c}4^{\underline{a}} \\
\text { série } / 5^{\circ} \text { ano }\end{array}$ & - & - & $\begin{array}{l}\text { Est } \\
\text { adual }\end{array}$ & * \\
\hline \multirow[t]{2}{*}{ eves $^{\text {Br }}$} & série/5을 ano & 2.9 & 3.9 & $\begin{array}{l}\mathrm{Mu} \\
\text { nicipal }\end{array}$ & $\begin{array}{r}\text { Não } \\
\text { atingiu a meta }\end{array}$ \\
\hline & $8^{\mathrm{a}}$ & 3.5 & 4.0 & $\begin{array}{l}\mathrm{Mu} \\
\text { nicipal }\end{array}$ & $\begin{array}{r}\text { Não } \\
\text { atingiu a meta }\end{array}$ \\
\hline \multirow[t]{4}{*}{$\begin{array}{r}\mathrm{Cu} \\
\text { rralinho }\end{array}$} & série/5을 ano & 2.6 & 3.6 & $\begin{array}{l}\mathrm{Mu} \\
\text { nicipal }\end{array}$ & $\begin{array}{r}\text { Não } \\
\text { atingiu a meta }\end{array}$ \\
\hline & $\begin{array}{c}8^{\mathrm{a}} \\
\text { série/9ㅇ ano }\end{array}$ & 3.2 & 3.8 & $\begin{array}{l}\mathrm{Mu} \\
\text { nicipal }\end{array}$ & $\begin{array}{r}\text { Não } \\
\text { atingiu a meta }\end{array}$ \\
\hline & $\begin{array}{c}4^{\mathrm{a}} \\
\text { série/5응 ano }\end{array}$ & 2.2 & 3.6 & adual ${ }^{\text {Est }}$ & $\begin{array}{c}\text { Não } \\
\text { atingiu a meta }\end{array}$ \\
\hline & $\begin{array}{c}8^{a} \\
\text { série/9o ano }\end{array}$ & 2.2 & 3.7 & $\begin{array}{l}\text { Est } \\
\text { adual }\end{array}$ & $\begin{array}{c}\text { Não } \\
\text { atingiu a meta }\end{array}$ \\
\hline o ${ }^{\text {Sã }}$ & $\begin{array}{c}4^{\mathrm{a}} \\
\text { série/5응 ano }\end{array}$ & 3.3 & 3.4 & $\begin{array}{l}\mathrm{Mu} \\
\text { nicipal }\end{array}$ & $\begin{array}{c}\text { Não } \\
\text { atingiu a meta }\end{array}$ \\
\hline
\end{tabular}




\begin{tabular}{|c|c|c|c|c|c|}
\hline \multirow{3}{*}{$\begin{array}{c}\text { Sebastião } \\
\text { da Boa } \\
\text { Vista }\end{array}$} & $\begin{array}{c}8^{\mathrm{a}} \\
\text { série } / 9^{\circ} \text { ano }\end{array}$ & 3.4 & 3.5 & $\begin{array}{l}\mathrm{Mu} \\
\text { nicipal }\end{array}$ & $\begin{array}{l}\text { Não } \\
\text { atingiu a meta }\end{array}$ \\
\hline & $\begin{array}{c}4^{\underline{a}} \\
\text { série/5을 ano }\end{array}$ & - & - & $\begin{array}{l}\text { Est } \\
\text { adual }\end{array}$ & $*$ \\
\hline & $\begin{array}{c}8^{\underline{a}} \\
\text { série/9o ano }\end{array}$ & - & - & $\begin{array}{l}\text { Est } \\
\text { adual }\end{array}$ & $*$ \\
\hline
\end{tabular}

Fonte: (INSTITUTO NACIONAL DE ESTUDOS E PESQUISAS EDUCACIONAIS ANÍSIO TEIXEIRA, 2013).

* Sem média na Prova Brasil 2013: Não participou ou não atendeu os requisitos necessários para ter o desempenho calculado.

Quadro 5 - Demonstrativo da situação dos municípios da Microrregião do Arari em relação ao IDEB (2013).

\begin{tabular}{|c|c|c|c|c|c|}
\hline Município & Série/Ano & $\begin{array}{l}\text { IDEB } \\
\text { observado }\end{array}$ & $\begin{array}{l}\text { Meta } \\
\text { Projetada }\end{array}$ & Rede de Ensino & Observação \\
\hline \multirow[t]{4}{*}{$\begin{array}{c}\text { Cachoeira do } \\
\text { Arari }\end{array}$} & $\begin{array}{c}4^{\underline{a}} \\
\text { série/5을 ano } \\
\end{array}$ & 3.1 & 3.2 & Municipal & $\begin{array}{l}\text { Não atingiu a } \\
\text { meta }\end{array}$ \\
\hline & $\begin{array}{c}8^{\underline{a}} \\
\text { série/9o ano }\end{array}$ & - & - & Municipal & * \\
\hline & $\begin{array}{c}4^{\underline{a}} \\
\text { série } / 5^{o} \text { ano }\end{array}$ & 3.3 & 3.7 & Estadual & $\begin{array}{l}\text { Não atingiu a } \\
\text { meta }\end{array}$ \\
\hline & $\begin{array}{c}8^{a} \\
\text { série/9o ano }\end{array}$ & 3.4 & 3.3 & Estadual & Atingiu a meta \\
\hline \multirow[t]{2}{*}{ Chaves } & $\begin{array}{c}4^{\underline{a}} \\
\text { série } / 5^{\circ} \text { ano }\end{array}$ & 2.9 & 3.9 & Municipal & $\begin{array}{l}\text { Não atingiu a } \\
\text { meta }\end{array}$ \\
\hline & $\begin{array}{c}8^{{ }^{\mathrm{a}}} \\
\text { série/9o ano }\end{array}$ & 3.7 & 3.7 & Municipal & Atingiu a meta \\
\hline \multirow[t]{2}{*}{ Muaná } & $\begin{array}{c}4^{\underline{a}} \\
\text { série/5을 ano }\end{array}$ & 3.5 & 3.7 & Municipal & $\begin{array}{l}\text { Não atingiu a } \\
\text { meta }\end{array}$ \\
\hline & $\begin{array}{c}8^{\mathbf{a}^{-}} \\
\text {série/9aa ano }\end{array}$ & 3.1 & 4.2 & Municipal & $\begin{array}{c}\text { Não atingiu a } \\
\text { meta }\end{array}$ \\
\hline \multirow[t]{4}{*}{$\begin{array}{l}\text { Ponta de } \\
\text { Pedras }\end{array}$} & $\begin{array}{c}4^{\underline{a}} \\
\text { série/5ㅇa ano }\end{array}$ & 3.4 & 3.8 & Municipal & $\begin{array}{l}\text { Não atingiu a } \\
\text { meta }\end{array}$ \\
\hline & $\begin{array}{c}8^{a} \\
\text { série/9o ano }\end{array}$ & 3.1 & 4.2 & Municipal & $\begin{array}{c}\text { Não atingiu a } \\
\text { meta }\end{array}$ \\
\hline & $\begin{array}{c}4^{\underline{a}} \\
\text { série } / 5^{\circ} \text { ano } \\
\end{array}$ & 3.7 & 4.1 & Estadual & $\begin{array}{c}\text { Não atingiu a } \\
\text { meta }\end{array}$ \\
\hline & $\begin{array}{c}8^{{ }^{\mathrm{a}}} \\
\text { série/9o ano }\end{array}$ & 3.7 & 4.1 & Estadual & $\begin{array}{l}\text { Não atingiu a } \\
\text { meta }\end{array}$ \\
\hline \multirow[t]{2}{*}{ Salvaterra } & $\begin{array}{c}4^{\underline{a}} \\
\text { série/5ㅇa ano }\end{array}$ & 3.4 & 3.9 & Municipal & $\begin{array}{c}\text { Não atingiu a } \\
\text { meta }\end{array}$ \\
\hline & $\begin{array}{c}8^{\mathrm{a}} \\
\text { série/9aa ano }\end{array}$ & 3.6 & 4.0 & Municipal & $\begin{array}{l}\text { Não atingiu a } \\
\text { meta }\end{array}$ \\
\hline \multirow[t]{2}{*}{$\begin{array}{c}\text { Santa Cruz do } \\
\text { Arari }\end{array}$} & $\begin{array}{c}4^{\underline{a}} \\
\text { série/5을 ano }\end{array}$ & 4.4 & 3.3 & Municipal & Atingida a meta \\
\hline & $\begin{array}{r}8^{a} \\
\text { série/9o ano } \\
\end{array}$ & 3.1 & 3.0 & Estadual & Atingida a meta \\
\hline \multirow[t]{2}{*}{ Soure } & $\begin{array}{c}4^{\underline{a}} \\
\text { série/5aa ano }\end{array}$ & 3.7 & 3.9 & Municipal & $\begin{array}{c}\text { Não atingiu a } \\
\text { meta }\end{array}$ \\
\hline & $8^{\mathrm{a}}$ & 2.8 & 3.6 & Estadual & Não atingiu a \\
\hline
\end{tabular}




\section{\begin{tabular}{|l|c|c|c|c|}
\hline & série/9ำ ano & & & meta \\
\hline
\end{tabular}} 2013).

* Número de participantes na Prova Brasil insuficiente para que os resultados sejam divulgados.

Os quadros acima retratam, por si mesmos, a situação de descaso com a população infanto-juvenil amazônica marajoara. Os índices de desenvolvimento humano, educacional e de saúde tão ruins mostram que as políticas econômicas e sociais pouco têm atendido as condições de vida dessa gente no que se refere a habitação, saneamento, saúde, nutrição, infraestrutura e acesso à educação (RIBEIRO et al., 2015).

Os dados evidenciados nos indicadores sociais dão conta das inúmeras dificuldades de sobrevivência da população marajoara nos dezesseis municípios da Mesorregião.

A realidade social de pobreza e miséria tem marcado a vida dos ribeirinhos da Mesorregião do Marajó, explicitada na introdução do IPS Amazônia (2014) ao afirmar que "o cidadão comum desta região enfrenta enormes deficiências em quase todos os componentes do progresso social", o que se comprova nos baixos Índices de Desenvolvimento Humano (IDH) e de Desenvolvimento da Educação Básica (IDEB), na falta de políticas públicas para saúde, educação, infraestrutura e transporte, por exemplo. Ribeiro (2006, p. 280) salienta que "[...] em nenhuma outra região brasileira a população enfrenta tão duras condições de miserabilidade quanto os núcleos caboclos dispersos pela floresta [...]”.

\section{CONCLUSÕES DO ESTUDO}

O presente estudo teve como objetivo analisar os índices de desenvolvimento social no Estado do Pará, sobretudo na região da Amazônia Marajoara, por meio de alguns indicadores sociais como IDHM, IDEB, IDSUS e IBEU-Municipal que mostram a situação socioeconômica dos municípios e da população paraense. Esse quadro nos dá subsídios para discutirmos as condições da população ribeirinha do Norte do Brasil.

Para esse propósito consideramos alguns aspectos de caráter geral que as pesquisas em fontes diversificadas foram capazes de levantar, entre os quais o forte indício de que os 16 (dezesseis) municípios do Marajó tenham sido formados a começar da doação de terras pelo sistema de sesmarias, a datar do século XVIII. O processo histórico de ocupação da região gerou o acúmulo de terras nas mãos de poucos, originando grandes latifúndios incansavelmente explorados em seus recursos naturais, deixando pouquíssimas compensações para a população local. Sistema que explora e coloca a população na condição de servil, que 
ainda no século XXI marca a história da Amazônia.

Outro ponto a destacar é que apesar de ser uma região de belezas naturais inigualáveis, é também a região com os menores índices de indicadores sociais do Brasil, incluído aí o município com o menor IDH, Melgaço/PA. Outros indicadores que escancaram as desigualdades sociais no Marajó e mostram a fragilidade das políticas públicas são: IDEB, IDSUS e IBEU-Municipal, que demonstram quão distante a Mesorregião do Marajó está dos indicadores mínimos necessários para uma qualidade de vida aceitável para seus povos. Os problemas se assentam, sobretudo, na insuficiência ou ausência de políticas públicas nas áreas da saúde, educação, saneamento, habitação e infraestrutura, que nega aos amazônidas seus direitos básicos estabelecidos na legislação nacional.

As dificuldades de acesso aos serviços de qualidade pela população concentram-se principalmente nas áreas de saúde e educação, afetando diretamente as crianças. Embora exista um Posto de Saúde em algumas comunidades, não há médicos, enfermeiros e odontólogos para atender a população, apesar dos auxiliares de enfermagem existentes realizarem os atendimentos básicos, comprometidos pela falta de materiais e medicação adequados. O pré-natal, o acompanhamento na primeira infância e o esquema de vacinação só existem na sede dos municípios.

O estudo também apurou que a educação é uma área que se recente da falta de recursos para melhoria da sua estrutura física, materiais pedagógicos e tecnológicos, além da falta de recursos humanos, especialmente professores de disciplinas específicas.

O estudo revelou ainda que o combate à miséria na Amazônia deve focar nas seguintes estratégias: transferência de renda, segurança alimentar, saneamento, habitação, saúde, educação e aprimoramento da qualidade dos serviços públicos oferecidos, o que consideramos como opções inteligentes para enfrentamento das problemáticas socioambientais da região.

\section{REFERÊNCIAS}

ARAÚJO, Sônia Maria Silva. Cultura e Escolas-de-fazenda na ilha do Marajó: um estudo com base em Raymond Williams. 2002. 253f. Tese (Doutorado) Programa de Pós-Graduação em Educação da FEUSP, Universidade de São Paulo, São Paulo, 2002.

BRASIL. Constituição da República Federativa do Brasil de 1988. Nós, representantes do povo brasileiro, reunidos em Assembleia Nacional Constituinte para instituir um Estado Democrático, destinado a assegurar o exercício dos direitos sociais...Diário Oficial da União, Brasília, 5 out. 1988. Disponível em: <http://www.planalto.gov.br/ccivil_03/constituicao /constituicao.htm> Acesso em: 14 de fevereiro de 2016. 
CASTRO, Orlando. Amazônia: espaço e tempo. Belém: Vitória, 2013.

GONÇALVES, Carlos Walter Porto. Amazônia, Amazônias. 3. ed. São Paulo: Contexto, 2012.

GONÇALVES, Carlos Walter Porto. Da geografia às geo-grafias: um mundo em busca de novas territorialidades. CLACSO, 2002. Disponível em: $<$ http://biblioteca.clacso.edu.ar/clacso/gt/20101018013328/11porto.pdf $>$. Acesso em: 20 dez. 2016.

ÍNDICE DE DESEMPENHO DO SUS. Índice de Desempenho do Sistema Único de Saúde. Brasília: IDSUS, 2016. Disponível em: <http://idsus.saude.gov.br/>. Acesso em: 10 maio 2016.

ÍNDICE DE PROGRESSO SOCIAL AMAZÔNIA. [S. 1.]: IPS, 2014. Índice de Progresso Social na Amazônia brasileira. Disponível em: <http://www. ipsamazonia.org.br/publicacao>. 24 mar. 2016.

INSTITUTO BRASILEIRO DE GEOGRAFIA E ESTATÍSTICA. Atlas do Desenvolvimento Humano: ranking - todo o Brasil Rio de Janeiro: IBGE, 2010a. Disponível em: <http://www.atlasbrasil.org.br/2013/pt/ranking>. Acesso em: 14 maio 2016.

INSTITUTO BRASILEIRO DE GEOGRAFIA E ESTATÍSTICA. Cidades: Pará Curralinho. Rio de Janeiro: IBGE, 2010b. Disponível em: $<$ http://cidades.ibge.gov.br/xtras/perfil.php?codmun=150280>. Acesso em: 24 abril 2016.

INSTITUTO BRASILEIRO DE GEOGRAFIA E ESTATÍSTICA. Perfil do Estado do Pará 2010. Rio de Janeiro: IBGE, 2010c. Disponível em: $<$ http://www.ibge.gov.br/estadosat/perfil.php?sigla=pa>. Acesso em: 11 set. 2015.

INSTITUTO NACIONAL DE ESTUDOS E PESQUISAS EDUCACIONAIS ANÍSIO TEIXEIRA. Curralinho. Brasília: INEP, 2013. Disponível em: <http://ideb.inep.gov.br/>. Acesso em: 24 mar. 2016.

INSTITUTO BRASILEIRO DE GEOGRAFIA E ESTATÍSTICA. Dados da Área Territorial Brasileira, Consulta por Município - Resultados. Rio de Janeiro: IBGE, 2010d. Disponível em: <http://www.ibge.gov.br/home/geociencias/areaterritorial/ area.php?nome $=\%>$. Acesso em: 14 mar. 2016.

INSTITUTO NACIONAL DE ESTUDOS E PESQUISAS EDUCACIONAIS ANÍSIO TEIXEIRA. Relatório Territorial do Marajó. Rio de Janeiro: IPEA, 2015.

INSTITUTO BRASILEIRO DE GEOGRAFIA E ESTATÍSTICA. Divisão regional do Brasil em mesorregiões e microrregiões geográficas. Rio de Janeiro: IBGE, 1990. Disponível em: <biblioteca.ibge.gov.br/visualizacao/.../Divisao\%20 regional_v01.pdf> Acesso em: 10 jun. 2016.

OBSERVATÓRIO DAS METRÓPOLES. Instituto Nacional de Ciência e Tecnologia. Municipal: Índice de Bem-Estar Urbano dos Municípios Brasileiros. Relatório. Observatório das Metrópoles/IPPUR/UFRJ. Organização de Luiz Cesar de Queiroz Ribeiro e Marcelo Gomes Ribeiro. Rio de Janeiro: Observatório, 2016. Disponível em: 
$<$ http://observatoriodasmetropoles.net/images/abook_file/ibeumunicipal_final.pdf $>$. Acesso em: 15 jan. 2017.

PACHECO, Agenor Sarraf. A conquista do ocidente marajoara: índios, portugueses e religiosos em invenções históricas. In: SCHAAN, Denise Pahl; MARTINS, Cristiane Pires. (Org.). Muito além dos campos: arqueologia e história na Amazônia Marajoara. Belém: GKNORONHA, 2010, p. 13-31. Disponível em: $<$ http://portal.iphan.gov.br/uploads/publicacao/PubDivArq_MuitoAlemCampos_m.pdf $>$. Acesso em: 5 set. 2016.

PACHECO, Agenor Sarraf. En el Corazón de la Amazonía: identidades, saberes e religiosidades no regime das águas marajoaras. 2009. 354f. Tese (Doutorado) - Pontifícia Universidade Católica de São Paulo, São Paulo, 2009b. Disponível em: $<$ https://sapientia.pucsp.br/handle/handle/13141>. Acesso em: 15 set. 2017.

PACHECO, Agenor Sarraf. História e literatura no regime das águas: práticas culturais afroindígenas na Amazônia Marajoara. Revista Amazônia, v.1, n.2, p. 406-441, 2009a, Disponível em: <http://periodicos.ufpa.br/index.php/amazonica/article/ view/297>. Acesso em: 15 set. 2017.

PARÁ. Instituto de Desenvolvimento Econômico, Social e Ambiental do Pará. Indicadores de Qualidade Ambiental dos Municípios da Região de Integração Marajó 2012. Pará: FAPESPA, 2012. Disponível em: $\quad<$ http://www.fapespa.pa. gov.br/produto/relatorios/44?\&mes=\&ano=2013>. Acesso em: 4 mar. 2016.

PINTO, Lúcio Flávio; KZAM, Áthila Lima. A Amazônia decifrada. Belém: edição dos autores, 2012.

PROGRAMA DAS NAÇÕES UNIDAS PARA O DESENVOLVIMENTO. O que é IDHM. Brasília: $\quad 2016 . \quad$ DNUD, 24 em: $<$ http://pnud.org.br/IDH/IDHM.aspx?indiceAccordion=0\&li=li_IDHM>. Acesso em: 24 mar. 2016.

\section{PROGRAMA DAS NAÇÕES UNIDAS PARA O DESENVOLVIMENTO. Ranking IDHM} Municípios 2010. Brasília: PNUD, 2010. Disponível em: $<$ http://pnud.org.br/atlas/ranking/Ranking-IDHM-Municipios-2010.aspx>. Acesso em: 2010.

QUIJANO, Aníbal. Colonialidade do poder, eurocentrismo e América Latina. CLACSO, 2005. Disponível em: <http://biblioteca.clacso.edu.ar/clacso/sursur/20100624103322/12_Quijano.pdf> acesso em: 20 jan. 2017.

RABELO, Eleni Bonifácio; NEVES, Ivânia dos Santos. Nas palavras de Dalcídio Jurandir: "Marajó", de rios campos e florestas, às contradições sociais. In: CONGRESSO INTERNACIONAL FLUXOS E CORRENTES: TRÂNSITOS E TRADUÇÕES LITERÁriAS, 14., 2014. Pará. Anais...Pará: ABRALIC, 24 a 26 de set. p. 384-396, 2014. Disponível em: <http://www.abralic.org.br/anais/arquivos/2014_1434476212.pdf>. Acesso em: 15 set. 2017.

ROSEMBERG, Fúlvia. Criança pequena e desigualdade social no Brasil. [S. 1.]: Do Autor, 2017.

Disponível em: $<$ http://www.diversidadeducainfantil. 
org.br/PDF/CRIAN\%C3\%87A\%20PEQUENA\%20E\%20DESIGUALDADE\%20SOCIAL \% 20NO\%20BRASIL\%20-\%20F\%C3\%BAlvia\%20Rosemberg.pdf>. Acesso em: 12 fev. 2017.

RIBEIRO, Maria Sílvia et al. Estudos sociais da infância. In: ARTES, Amélia; UNBEHAUM, Sandra. Escritos de Fúlvia Rosemberg. São Paulo: Cortez: Fundação Carlos Chagas, 2015, p. 29-59.

RIBEIRO, Darcy. O povo brasileiro: a formação e o sentido do Brasil. São Paulo: Companhia das Letras, 2006.

SOUZA, Alexandre Augusto Cals e. Políticas educacionais na Amazônia: estado, democracia, sociedade civil e participação. Jundiaí: Paco Editorial, 2015.

SILVA, Joel Pantoja da. Memórias Tupi em narrativas orais no rio Tajapuru - Marajó das Florestas - Pa. 2013. 120f. Dissertação (Mestrado)- Universidade da Amazônia, Belém/PA, 2013.

SOARES, Eliane Cristina Lopes. Família, compadrio e relações de poder no Marajó (séculos XVIII e XIX). 2010. 204f. Tese (Doutorado) - Pontifícia Universidade Católica de São Paulo, São Paulo, 2010. Disponível em: $<$ https://sapientia.pucsp.br/bitstream/handle/13219/1/Eliane\%20Cristina\%20Lopes\%20Soares .pdf $>$. Acesso em: 14 set. 2017.

TAVARES, Maria Goretti da Costa. A formação territorial do espaço paraense: dos fortes à criação de municípios. Revista Acta Geográfica, ano II, n. 3, jan./jun. 2008, p.59-83. Disponível em: <https://revista.ufrr.br/actageo/article/view/204>. Acesso em: 7 set. 2017.

TEIXEIRA, José Ferreira. O Arquipélago de Marajó. In: CONGRESSO BRASILEIRO DE GEOGRAFIA REALIZADO NA CIDADE DO RIO DE JANEIRO (DISTRITO FEDERAL), 10., 1944. Rio de Janeiro. Anais...Rio de Janeiro: Serviço gráfico do IBGE, 1952, 7 a 16 de setembro de 1944. p. 713-807. v.8.

UNIVERSIDADE FEDERAL DO PARÁ. Ministério do Desenvolvimento Agrário. Relatório Analítico do Território do Marajó 2012. Para: MDA, 2012. Disponível em: $<$ http://sit.mda.gov.br/download/ra/ra129.pdf>. Acesso em: 10 mar. 2015.

VERÍSSIMO, Tatiana Corrêa; PEREIRA, Jakeline. A floresta habitada: história da ocupação humana na Amazônia. Belém: Instituto do Homem e Meio Ambiente da Amazônia (IMAZON), 2014. 